openings $f f$, the gas having then a free passage from the pipe $a$ through the two sides of the frame $b b$, and into and through the plug $h$. It will be seen on reference tu Fig. 6 , that a small turn of the plug is sufficient to open or close the cock. $k$ is a pipe screwed into the tube $e$, and leading to the burner $l$. $m$ is a projection at the lower end of the plug, and $n$ is a pin passed through the same. The plug is supported on the point of the pivot on which a magnet turns, so that very little power is required to turn the plug. $o$ is a permanent magnet, which may be either cast in steel, with the two projecting pieces $p p$, or made out of a steel bar bent into the proper shape, and in this case the projections $p$ are produced by screwing in two pieces of metal. $y$ is the pivot on which this magnet turns ; it is passed through a vertical hole in the magnet, and fixed by a screw $r$. The lower end of the pivot rests in a steel step $s$, which is supported by a small wooden beam $t$, secured to the ends of the wooden bobbin $2 t . v$ is the induction-coil; it is composed of a core of soft iron wire:, two layers of primary wires wound with covered copper wire of about No. $20 \mathrm{BWG}$, and upon these about ten to fifteen layers of secondary wire of about No. 40 BWG. The primary wires $w w$ form part of the circuit by which the lamps to be lighted or extinguished simultaneously are connected. One end of the secondary coil is connected to an insulated wire $x$, leading to the burner $l$, where it terminates in a platinum point, and the other end is connected to the frame b, or to any other metallic part of the apparatus, so as to be in metallic connection with the burner. The insulated wire $x$ passes through an earthenware support $y$ (seen in plan in Fig. 9), fixed to the pipe $k$. The solt iron core projects about threeeighths of an inch from each end of the wooken bobbin 76 . The bobbin is fastened to wooden supports $z \approx$, which are fixed to the frame $b$ by screws $z^{3} z^{1}$.

Fig. 10 (for the use of which we are indehted to the Society of Arts is a view of the complete anparatus as atlachtel to a sis hmp.

\section{AHERICAN SCIENCE}

T11E March number of the Amiricun Fournal of Sicince opens with a valuable paper, in which Prof. Norton cullates the various observations made on Cogrgia's comet. The theory of cometary phenomena he arrives at is (briefly) that the direct action of the sun on the side of the nucleus exposed to the solar rays is to form an envelope of gaseous carbonic oxide. This envelope of diamagnetic gas is traversed by the ideal limes of magnetic force proceeding from the nucleus, which are also lines of contuction through the gas. The electricity stt free by the ascending currents of gas, by reason of the diminished gaseous pressure, is propagated along these lines, and the impulsive force of the electric currents detaches streams of the successive molecules of the gas in the direction of the lines of conduction. Both the nucleus and the sun exert repulsive forces on the escaping molecules; but their effective actions may be either repulsive or attractive, according as their attraction prevails over the attraction of gravitation, or the reverse. The author elucidates this theory at some length.

In a reply to Mr. Mallet's review (in the Fhilosophical Magasiuc) of General Ablott's paper on the velocity of transmission of earth-waves, in which the value and accuracy of the Hallet's Point observations were doubted, the General describes some new observations on the subject, which seen to establish these points : $x$. A high magnifying power of telescope is essential in seismometric observations. 2. The more violent the initial shock the higher is the velocity of transmission. 3. This velocity diminishes as the general wave advances. 4. The movements of the earth's crust are complex, consisting of many short waves first increasing and then decreasing in amplitude, and, with 2 . detonating explosive, the interval between the first wave and the maximum wave, at any station, is shorter than with a slowburning explosive.

A new method for decomposition of chromic iron, proposed by Mr. Smith, consists in exposing it (in an exceedingly fine state) with bromine to a temperature of $180^{\circ} \mathrm{C}$. from two to three days. Prof. Marsl furnishes an account of some new Dinosaurian rep. tiles. - Prof. Kimball describes some experiments on journal friction at low speeds. - There are also notes on some reactions of silver chloride and bromide, brightness of the satellites of Uranus, \&c.

The new number of Appralichin, the journal of the Appalachian Mountain Club, contains a valuable address by the presi- dent, Dr. S. HI. Scudder, in which he reviews the principal scientific expeditions in the United States during the past year. Dr. Scudder himself is attached to the Hayden Survey, and made the discovery of the beds of fossil insects at Florissant, near Manitou, Colorado. During the past year 20,000 fossil insects have been exhumed from this quarry.

\section{UNIVERSITY AND EDUCATIONAL INTELLIGENCE}

CAMBRIDGE.--The fifth and final report of the Syndicate appointed in May, 1875, to consider the requirements of the University in different departments of study, has been issued. The Syndicate have considered the question of the residence to be required of professors. They are of opinion that it is desirable-(r) that the time for which the University may require the residence of professors shall be left to be determined by the University in the case of each professorship, without any general statutable restriction; (2) that no professor shall be considered to satisfy the condition of residence who is not for the time required making his home within a mile and a half of Great St. Mary's Church, unless special permission, available for not more than one year at a time, but renewable, be granted by the Vice-Chancellor and Sex Viri, and that such permission shal not be granted unless the Vice-Chancellor and Sex Viri are satisfied that the professor has made such arrangements as will secure his being reasonably accessible in Cambriclge during term time. The Syndicate have also had under their consideration the importance of individual personal intercourse between students and teachers, and it has also been suggested that the inspection and revision of stuclents' note-books by the teacher may in many cases be of considerable use. The precise mannirer in which such personal intercourse may be most effectually secured will probably vary sery much in different subjects and for different teachers, but it seems important that the arrangements should be such that the professor himself may in all cases see a portion of the work of his class, so as to make himself accurately accuainted with their wants. The Syndicate have referrel to the Board of Medical Studie: the question whether it is desirable to found a complete medical school in Cambridge so as to make it possible for a stuklent to complete his whole medical course here, or whether it is: bettc: for all concerned, while making the teaching at Cambridge as perfect as possible in the scientific subjects which are the basi; of medicine, to leave students to carry on elsewhere the greater part of their clinical studies and most of what relates directly to the practice of medicine. The reply of the Board of Medical Studies states that they consider it inexpedient that stuclent: should complete their whole professional education at any" single medical school, and that it is therefore desirable that students should pursue their studies away from Cambridge for a year or more before commencing practice, either before or after their final M.L. examination. They believe, however, that it would be in most cases advantageous to students to carry their medical studies in Cambridge further than is usually clone at present, and in some cases as far as the final M.B. examination, and they are therefore of opinion that the University should provide systematic instruction in all the subjects necessary for a medical degree, as is done at other Universities. In order that this may be carried out satisfactorily the Board of Mecilical Studies think that the University should provide:-I. A Professor of Pathology. 2. A Professor of Surgery. 3. Systematic teaching in (I) midwifery and the diseases peculiar to women (2) medical jurisprudence; (3) sanitary science; (4) mental cliseases. 4. Systematic clinical teaching.

R.G.S. Public Schools' Prize Medals.-The following is the award of the Public Schools' Prize Medals annually given by the Royal Geographical Society:-Physical Geography-Gold1 Medallist, William John Newton, of Liverpool College; Silver Medallist, Christopher Mounsey Wilson, of Clifton Collere; Honourably Mentioned-E. G. Harmer, University Collere School; M. H. Clifford and M. A. Soppitt, of Dulwich Collere: and J. S. G. Pemberton, of Eton College. Political Geosraphy-Gold Medallist, William Wallis Ord, of Dulwich College; Silver Medallist, George Arnold Tomkinson, of Haileybury College; Honourably Mentioned-A. R. Ropes, of the City of London School; A. Kay, of Rossall School; and D. Bowie, of Dulwich College. 